УДК 330.862

\title{
B.В. Матвеев
}

\section{АНАРХИЯ КАК ИНСТИТУЦИОНАЛЬНОЕ ОТРИЦАНИЕ ГОСУДАРСТВА}

Статья посвящена исследованию анархических трактовок экономики. Данное исследование является актуальным по той причине, что современное государство оказалось весьма неэффективным в решении проблем, связанных с возникновением и распространением эпидемии COVID-19. Противоречие между государством как политическим институтом и населением многих стран вышло на новый, чрезвычайно высокий, уровень противостояния. Методологической базой исследования являются базовые экономические теории, включая экономику общественного сектора и институциональную экономику. В результате автор обосновал вывод о том, что в условиях жёсткого кризиса, когда государство оказывается не в состоянии оперативно решать новые проблемы, достаточно быстро формируются негативные суждения о роли современного государства как политического института, который должен решать социально-экономические проблемы. В этих условиях начинают приобретать популярность анархические трактовки развития общества, которые в принципе отрицают необходимость государства. Анархисты в качестве базового постулата продвигают положение о том, что люди сами, без какого-либо участия государства, в состоянии решать как личные, так и коллективные, и общественные проблемы. Однако ход развития событий в США опровергает данное утверждение. В ситуации отсутствия государства как актора общественных процессов реальная власть переходит к криминальным группировкам, которые легко идут на самое жёсткое насилие по отношению к гражданам. Результаты исследования могут быть использованы для формирования государственной и региональной экономической политики, а также в курсе преподавания предмета «Институциональная экономика».

Ключевые слова: анархия, общество, государство, насилие, кризис, глобализм, коммунизм, экономические институты.

DOI: $10.35634 / 2412-9593-2020-30-4-494-502$

Анархизм - это существенно больше, чем антигосударственничество. В силу того, что государство в первую очередь служит реализации интересов тех лиц, которые находятся во власти, то это позволяет данным социальным группам оказывать доминирующее влияние на развитие государства, в том числе определение важности проблем и очерёдности их решения.

Государство достаточно давно выступает в качестве объекта критики сторонников анархии. Немецкий философ Ф. Ницше характеризовал государство как «смерть народов», доказывал необходимость освободиться от идолопоклонства в абсурдной форме почитания государства. По его мнению, убеждение, что долг человека - это служение государству, по своей сути есть проявление крайней тупости. Ницше обвиняет государство в постоянной лжи [1].

Заметная роль в развитии политической философии анархизма в Северной Америке и Европе в первой половине XX в. принадлежит Э. Гольдман, которая доказывала, что анархизм есть философия нового общественного строя, основанного на свободе, неограниченной какими бы то ни было человеческими законами. Государство как форма организации общества основано на насилии, поэтому является ложным, вредным и совершенно ненужным [2].

Для Э. Гольдман характерна достаточно примитивная трактовка экономических отношений. Она признает, что общественный строй основывается, безусловно, на материальной базе и личном экономическом интересе. Однако тут же безапелляционно утверждает: главное зло сегодняшнего дня заключается в экономике. В качестве идеальной экономической системы могут рассматриваться только добровольные производительные и распределительные ассоциации, постепенно развивающиеся в свободный коммунизм. Именно этим можно объяснить следующее абсолютно утопическое утверждение: «Совершенная личность возможна только в таком состоянии общества, где человек может свободно выбирать себе характер работы, условия работы, и самую работу. Ибо делать стол, строить дом или обрабатывать землю может быть для одного человека тем же, что для художника рисовать, для научного деятеля заниматься открытиями - работой вдохновения, страстного желания и глубокого интереса к делу, что дает человеку творческую силу [2].

В своей критике государства анархисты обращаются к хорошо известной работе Т. Гоббса «Левиафан», в которой говорится о том, что государство сосредотачивает в себе огромную силу. Это по- 
зволяет отдельно взятому человеку или группе лиц выступать от имени государства и подчинять себе волю других людей [3. С. 123].

По мнению Т. Гоббса, государство базируется на насилии и моральном авторитете. В качестве последнего может выступать церковь или официальная идеология. Авторитет необходим для обоснования могущества государства, который в идеальном варианте ничем не ограничен. Абсолютное могущество государства вызывает у человека чувство ужаса и беззащитности, причём люди сами заинтересованы в создании сильного государства. При всех своих недостатках государство, используя свою силу, выступает гарантом спокойной и достаточно хорошо материально обеспеченной жизни. Феномен государства, как утверждает Т. Гоббс, практически непостижим для простого человека, которому остаётся только преклоняться перед мощью и мудростью Левиафана [3. С. 123].

В то же время весьма интересна следующая реплика Т. Гоббса: «В самом деле, те, кто испытал обиду при монархии, именуют её тиранией, а те, кто недоволен аристократией, называют её олигархией. Точно так же те, кому причинено было огорчение при демократии, называют её анархией (что означает отсутствие правительства)» [3. С. 134]. Таким образом, любая форма организации государства имеет своих сторонников и противников, в числе последних наиболее известны сторонники анархизма.

Безусловным критиком государства был П.А. Кропоткин - создатель идеологии анархокоммунизма и один из самых влиятельных теоретиков анархизма. По мнению П. Кропоткина, происхождение государства определяется следующими причинами: во-первых, это экономика: «Само историческое развитие государства было вызвано не чем иным, как возникновением земельной собственности и желанием сохранить её в руках одного класса, который, таким образом, стал бы господствующим» [4]; во-вторых, классовые интересы правящих групп: «Дело в том, что государство - нечто гораздо большее, чем организация администрации в целях водворения «гармонии» в обществе, ... Это - организация, выработанная и усовершенствованная медленным путем на протяжении трех столетий, чтобы поддерживать права, приобретённые известными классами, и пользоваться трудом рабочих масс; чтобы расширить эти права и создать новые, которые ведут к новому закрепощению обездоленных законодательством граждан по отношению к группе лиц, осыпанных милостями правительственной иерархии. Такова истинная сущность государства» [4].

Особенно жёсткой критике подвергалась функция государства, связанная со сбором налогов, так как основа государственного бюджета - это именно налоги. В результате население любого государства из собственного кармана оплачивает то насилие, которое по отношению к ним осуществляет это государство.

По мнению П. Кропоткина, государство должно быть разрушено, что позволит возникнуть и получить развитие новой системе отношений между людьми «в тысяче центров на почве энергичной личности и групповой инициативы, на почве вольного соглашения» [5]. В противном случае государство раздавит личность и завладеет всеми областями человеческой деятельности.

Счастливое будущее П. Кропоткин описывал следующим образом: «...если бы громадный капитал ... стал общим достоянием - вместо того, чтобы оставаться частной собственностью, - то уже легко было бы завоевать настоящее довольство для всех. Силы, которыми мы располагаем, шли бы тогда не на ненужные и друг другу противоречащие работы, а на производство всего того, что нужно человеку для продовольствия, жилища, одежды, комфорта, для изучения наук и для разработки искусств» [6].

Однако создание такого общества невозможно без принципиальных нравственных изменений в личности человека. По мнению П. Кропоткина, анархической революции должен предшествовать подготовительный этап, в течение которого элементы альтруизма должны возникнуть и укрепиться в обществе. Это означало, что первоначально анархия возникала как некая субкультура в форме образа действия части людей: «Анархия - не утопия на будущие времена, а одухотворяющий принцип для действий во всякое время: сегодня, также как и завтра» [7].

Здесь анархисты не были единственными утопистами, которые искренне верили в реальную возможность достаточно быстро изменить суть человеческой личности. Можно вспомнить абсолютно утопические мысли В.И. Ленина о возможности построения коммунизма в кратчайшие исторические сроки: «Тому поколению, представителям которого теперь около 50 лет, нельзя рассчитывать, что оно увидит коммунистическое общество. До тех пор это поколение перемрёт. А то поколение, которому сейчас 15 лет, оно и увидит коммунистическое общество, и само будет строить это общество...Надо, чтобы Коммунистический союз молодежи воспитывал всех с молодых лет в сознательном и дисциплинированном труде. Вот каким образом мы можем рассчитывать, что те задачи, которые теперь поставлены, будут разрешены» [8. С. 317-318]. 
Теория анархизма в самой жёсткой форме утверждает, что характерной чертой любого государства является насилие. Кстати, аналогичную точку зрения высказывал М. Вебер, которому принадлежит следующее определение современного государства - это «организованный по типу учреждения союз господства, который внутри определённой сферы добился успеха в монополизации легитимного физического насилия как средства господства, и с этой целью объединил вещественные средства предприятия в руках своих руководителей, а всех сословных функционеров с их полномочиями, которые раньше распоряжались этим по собственному произволу, экспроприировал и сам занял вместо них самые высшие позиции» [9].

Применение насилия не зависит от того, какого типа это государство: монархическое или республиканское, либеральное или диктатура. Естественно, что в демократическом государстве с высоким уровнем конституционных гарантий правительства вынуждены обеспечивать своим гражданам бо́льшую степень свободы. Но даже демократические государства регулярно используют насилие при возникновении ситуации, которая может представлять для этого государства реальную или мнимую опасность. Поэтому сторонники анархизма утверждают, что государство при первой возможности с лёгкостью нарушает политические и экономические права своих граждан. Например, хорошо известное противостояние между правительством Великобритании и шахтёрами в 1984-1985 гг., когда консервативное правительство М. Тэтчер в весьма жёсткой форме расправилось и со стачкой, и с профсоюзами, а заодно и с большей частью отсталых отраслей промышленности. Однако с исчезновениями градообразующих шахт захирели и образованные ими города. Резко вырос уровень самоубийств, наркомании, преступлений, антиобщественного поведения. Если раньше шахтеры и их близкие были законопослушными гражданами, то отсутствие работы и безысходность разрушили их среду обитания. Людям стало не на что надеяться, не к чему стремиться. Ученые Шеффилдского университета подсчитали, что почти 100 тыс. чел. так никогда и не нашли другую работу. Многие и не пытаются это сделать и доживают свой век на пособие по безработице, затаив обиду на весь свет [10].

Очень много вопросов вызывает движение против глобализма, которое по своей сути во многом является проявлением анархизма.

Здесь следует упомянуть жёсткого критика современного государства, одного из самых известных теоретиков антиглобалистского движения Ноама Хомски. Он считает, что «концентрация богатства, естественно, приводит к концентрации власти, что, в свою очередь, направляет законодательство в пользу интересов богатых и сильных, тем самым еще больше повышая концентрацию власти и богатства. Различные политические меры, такие как фискальная политика, дерегуляция, и правила корпоративного управления предназначены для усиления концентрации богатства и власти. Это мы и наблюдаем в неолиберальную эпоху. Это замкнутый круг, постоянно прогрессирующий. Государство существует, чтобы обеспечивать безопасность и поддержку интересов привилегированных и могущественных слоев общества, в то время как остальной части населения остаётся переживать жестокую реальность капитализма. Социализм для богатых, капитализм для бедных» [11. С. 218]. Итогом этого является всё большее и большее различие в материальном достатке между богатыми и бедными.

При этом Н. Хомски крайне негативно высказывается в адрес той модели социализма, которая была реализована в Советском Союзе. Он считает, что отход от настоящего социализма, который следует понимать, как контроль трудящихся над производством, произошел сразу после событий октября 1917 г. при Ленине и Троцком. Поэтому феномен сталинизма можно достаточно легко объяснить тем, что все необходимые условия для его формирования и развития присутствовали уже в начале большевистского периода. Только при Сталине все это приняло чудовищные формы [11. С. 258].

Главная причина этого объясняется тем, что Ленин и Сталин на практике отказались от важнейшего элемента социалистического идеала: преобразование средств производства в собственность свободно ассоциированных производителей. В последующем это должно было позволить преобразовать социальные качества людей, которые станут по-настоящему свободными. Большевики, придя к власти, сразу же занялись подавлением освободительного потенциала человека, что является основой теории анархизма. Таким образом, никакой особой разницы между советским коммунизмом и корпоративно-государственным капитализмом нет [11. С. 263].

В 2000 г. выходит фундаментальная работа М. Хардта и А. Негри «Империя». Здесь необходимо сказать несколько слов об одном из авторов, который пытался соединить свои теоретические исследования с реальными политическими действиями. Это Антонио Негри - философ, теоретик современного коммунистического движения. Принимал самое активное участие в создании леворадикальной группы «Рабочая власть», которая затем была преобразована в группу «Рабочая автономия». 
В апреле 1979 г. А. Негри был арестован и обвинён в терроризме. Прокуратура пыталась доказать, что «Рабочая автономия» являлась «мозговым центром» левых экстремистов и связана с террористическим движением «Красные Бригады», которые в 1978 г. организовали похищение и убийство бывшего премьер-министра Италии, лидера партии христианских демократов Альдо Моро. Кроме того, А. Негри обвинялся в планировании свержения государственного строя Италии.

Авторы «Империи» утверждают, что современный процесс глобализации ведёт к формированию Империи (с большой буквы - замечание авт.). Процесс формирования и развития Империи был запущен благодаря двум принципиальным изменениям второй половины XX в.: крушение колониальной системы и крах советского эксперимента. Это привело, как думали авторы, к непреодолимому и необратимому процессу глобализации, политических, экономических, идеологических и культурных процессов, в которые были вовлечены практически все страны. Вместе с возникновением глобальных производств и глобальных рынков возникает и новый вид суверенитета. Империя становится политическим субъектом, которая достаточно эффективно регулировала эти глобальные процессы.

По мнению М. Хардта и А. Негри, процесс глобализации - это новый виток в развитии государства. Только на смену национальным государствам приходит Империя, которая «не создаёт территориальный центр власти и не опирается на жестко закрепленные границы или преграды. Это децентрированный и детерриториализованный, то есть лишенный центра и привязки к определённой территории аппарат управления, который постепенно включает всё глобальное пространство в свои открытые и расширяющиеся границы. Империя управляет смешанными, гибридными идентичностями, гибкими иерархиями и множественными обменами посредством модулирования командных сетей» [12. С. 12].

Империя имеет явное превосходство над населением и подчиняет его власти своей глобальной машины подобно новому Левиафану. Империя оказывается просто аппаратом захвата политической и экономической власти, существующим лишь за счет витальности масс.

Как отмечает Н.Н. Козлова, идея витальности обществ привлекает всё большее внимание интеллектуалов и политиков: «Витальность - слово многозначное. С одной стороны, под витальностью понимают мощь, напор жизни, с другой - с ним ассоциируется способность к выживанию, к балансированию на грани жизни и смерти. В современном языке тема витальности бытует больше во втором значении: «жить на грани выживания»» [13. С. 95].

Проблема выживания обостряется в ситуации кризиса или принципиальных технологических изменений. Э. Тоффлер с тревогой отмечает: «Безработица усиливает уход от дел, но ни одно современное общество не может позволить большинству рабочих, лишившихся работы в связи с остановкой производства, жить на свои собственные скудные ресурсы. Массовая безработица без какой-либо формы субсидии или доходов создаёт опасную политическую нестабильность, и это понимает каждый. Поэтому действительный вопрос состоит в том, как оплачивать уход от дел большого количества рабочих» [14]. Технологический прогресс и поступательное развитие общества не снимает с повестки дня проблему выживаемости граждан общества. Ситуация усугубляется по той причине, что социальные институты, составлявшие основу гражданского общества (семья, системы образования, здравоохранения и защиты правопорядка, социализации) пребывают в сильнейшем кризисе. По мере их деградации и разрушения на первый план выходит система тотального контроля [12. С. 306]. Как видим, М. Хардт и А. Негри критикуют современное общество на основе теории анархизма.

Современные анархисты, как и их предшественники, считают, что экономическое неравенство это результат насилия со стороны государства. Они утверждают, что государство по своей сути представляет собой систему организованного насилия для поддержания господства правящих классов, в первую очередь крупной буржуазии и представителей политической элиты. В то же время они признают, что порядок выполняется и поддерживается с согласия граждан общества, а не на одном голом насилии. Современные анархисты демонстрируют стремление выйти за чисто классовые ограничения. Всё большее внимание они уделяют процессу глобализации, который сопровождается разрушением традиционных местных культур и истощением природных ресурсов. Они считают, что процесс глобализации - это последний шаг к установлению тотального контроля не только над населением различных стран мира. Необходимо вести речь о создании системы контроля использования, без каких-либо исключений, всех видов ресурсов. Итогом этих процессов будет уничтожение того, что классифицируется как общественное достояние. Здесь речь идёт как об экономических, так и социальных, политических, культурных и иных процессах. 
Как и более ранние формы неравенства, глобальный капитализм порождает насилие. Однако для процесса глобализации характерна принципиальная особенность: в отличие от процессов, которые определяли развитие цивилизации в течение XVIII - первой половины XX в., современный этап определяется концентрацией огромного потенциала насилия в руках очень узкого круга акторов. Демонстративный отказ от государства продолжает оставаться одним из принципиальных признаков анархистской антиглобализации. При этом точно так же весьма жёстко отвергаются призывы тех, кто предлагает вернуться в старые добрые времена всеобщего благоденствия и национального суверенитета, когда национальное государство защитило нас от худших излишеств, когда, как уверены анархисты, государство, якобы, защищало своих граждан от экономического и политического господства крупных корпораций.

Здесь уместно упомянуть ещё одного известного российского теоретика и практика анархизма М.А. Бакунина: «Каждая логическая и искренняя теория государства по существу основана на использовании принципа авторитета: человеческие массы никогда не способны управлять собой, поэтому они должны подчиняться доброжелательному игу мудрости и справедливости, которое, так или иначе, навязывается им сверху»[15].

Солидарное мнение высказывает итальянский анархо-коммунист E. Malatesta, который был убеждён в необходимости ликвидации государства как выразителя политического порядка. Государство - это прежде всего насилие. Необходимо вести речь о создании общества свободных и равных граждан, основанном на гармонии интересов и добровольном участии в исполнении социальных обязанностей [16].

Государство может принимать различные политические формы: демократия, монархия, диктатура, для каждой из которых характерна собственная модель решения социально-экономических, политических и иных проблем. Современное государство влияет практически на все аспекты личной жизни граждан. Тем не менее, как считают сторонники теории анархизма, можно представить формы организации общества без государства.

П.А. Кропоткин в своей работе «Государство, его роль в истории» связывал формирование и развитие современного государства с крахом средневековых городов-государств, которые ещё в XII в. приводили людей к организации, основанной на свободном соглашении, на свободном почине личности, на вольной федерации тех, кто нуждается в ней [17]. Именно после этого краха, который он относит к XII - XV вв., формируются жёсткие централизованные институты управления, что стало стратегическим фактором развития новых экономических отношений: капитализм.

Анархисты разделяют общую точку зрения, согласно которой любая власть включает в себя ряд действий: от физического принуждения к влиянию и убеждению, и что это может осуществляться как открыто, так и тайно. Здесь речь идёт о потенциале насилия и готовности его использовать по отношению к другим людям для получения требуемого результата.

Именно по этой причине анархисты обосновали свою идею об упразднении (разрушении) государства. Сторонники анархо-синдикализма и анархо-коммунизма предполагали, что отмена государственной власти будет достигнута в форме экспроприация частной собственности и реализации принципа общего владения рабочих и крестьян. Синдикалистская идея R. Rocker заключалась в том, что борьба с государством должна принять форму солидарного добровольного и сознательного сотрудничества всех работников через управление всеми заводами [18].

Итак, анархизм определяет государство и власть как ненужное зло. Утверждается, что отмена государства положит конец политике насилия и репрессии по отношению к обществу и его гражданам. Это позволит создать новый гармоничный общественный строй. Граждане будут освобождены от необоснованных ограничений со стороны государства, что позволит им пользоваться своей свободой для достижения индивидуальных или общественных целей.

Популярность идей анархизма резко выросла в последнее время. Не является секретом, что современное государство далеко не всегда может быть эффективным. Социально-экономические, политические и иные проблемы начинают вызывать всё большее недовольство рядовых граждан страны. Рано или поздно накапливается некая критическая масса, которая может закончиться социальным взрывом. Как правило, это некий внешний фактор, который на первый взгляд кажется незначительным. Хотя последний резкий всплеск социального недовольства напрямую связан с низкой эффективностью государства в период эпидемии COVID-19. Вынуждая граждан страны жить в условиях изоляции с целью недопущения распространения эпидемии, государство создало благоприятные условия для формирования жёсткого недовольства политикой, которую осуществляет государство. 
В США всплеск недовольства был вызван гибелью в Миннеаполисе чернокожего Джорджа Флойда. Действия полиции, которые привели к трагедии, очень сложно оправдать. Однако личность Флойда вызывает очень много вопросов. За свои 46 лет он заработал пять тюремных сроков. По сути, он выходил из заключения, недолго был на свободе и вновь отправлялся за решётку. Первый срок он получил в 20 лет за кражу, последний - за ограбление.

Очень важно отметить то, что реальная причина гибели до сих пор не установлена. Первая судмедэкспертиза выявила, что на момент смерти он был под влиянием фентанила (опиоидный анальгетик, длительное употребление чревато развитием наркомании), а также в его организме имелись следы метамфетамина (психостимулятор с высоким потенциалом к формированию зависимости, в связи с чем отнесён к наркотическим веществам). Это позволяет согласиться с полицейскими, которые утверждали, что Флойд вёл себя неадекватно. Причина смерти - остановка сердца, возможно, из-за удушения (а возможно, из-за чего-то ещё, например, тех же наркотиков).

Вторая экспертиза, проведённая по настоянию его семьи, когда скандал уже разгорелся, пришла к выводу, что летальный исход наступил из-за удушения. Однако независимость и объективность такой экспертизы вызывает очень большие сомнения.

Поначалу протесты носили мирный характер, но очень быстро превратились в погромы, которые начинают быстро распространяться по другим городам США. Призывы к равенству и требования остановить полицейский произвол отодвинула личность Джорджа Флойда на задний план. Произошёл заурядный процесс превращения человека в символ. Уже практически никто не вспоминал, что он значительную часть своей жизни провёл в заключении.

Следует признать, что негритянские волнения в США происходят достаточно регулярно: Окленд (2010 г.), Флорида (2012г.), Лос-Анжелес, Чикаго, Нью-Йорк, Сан-Франциско (2013г.), Фергюсон (пригород Сент-Луиса, 2014г.), Балтимор (2015 г.). Главная причина этих волнений - различия в качестве жизни между белыми и чёрными гражданами страны. Согласно исследованию Института экономической политики (Economic Policy Institute, EPI), в 2015 г. чёрные американцы зарабатывали меньше, чем белые, и разрыв между средними доходами первых и вторых вырос по сравнению с 1979 г. Если в 1979 г. средняя почасовая оплата труда чёрных мужчин была на 22,2 \% ниже, чем труда белых, то к 2015 г. она стала ниже уже на $31 \%$. У чёрных женщин в 1979 г. оплата труда была на $6 \%$ ниже, чем у белых, в 2015 г. разрыв вырос до $19 \%$. Средний годовой доход домохозяйства белых американцев в 2015 г. составил 63000 долл. Это на 70 \% больше, чем средний доход домохозяйства чернокожих американцев, составивший 36898 долл. [19].

Экономическое неравенство подкрепляется в свою очередь значительным социальным неравенством. Согласно данным журнала The Economist, 72 \% тёмнокожих детей рождаются вне официального брака (белых - только 29 \%), большинство из них потом воспитываются в неполных семьях. 17-летний тёмнокожий ребенок демонстрирует сегодня такую же технику чтения и такой же уровень владения математикой, как и 13-летний белый ученик. Многие нарушают закон: к 35 годам один негр из десяти оказывается за решёткой; для белых - это один из 61 [20].

Отсюда вероятность поступления в колледж у белых школьников существенно увеличивается по сравнению с темнокожими абитуриентами. Следовательно, в итоге белокожие американцы имеют более высокий уровень образования и, как следствие, более высокий социальный статус, который закономерно ведет их к более высокому уровню благосостояния.

В государственную школу в США можно ходить только в районе проживания. Это автоматически делит школы на чёрные, которые находятся в неблагополучных районах, то есть плохие, и белые, в благополучных районах, то есть хорошие. Переехать в район с хорошей школой практически невозможно по причине высоких цен на недвижимость в хороших районах. Соответственно, в хорошие государственные школы ходят только дети из богатых семей и почти всегда это белые дети. Естественно, что поступить в хороший университет из плохой школы невозможно. Соответственно, у чернокожего ребенка практически нет шансов выбраться из этого замкнутого круга через систему социальных лифтов.

Всё это можно назвать институциональным расизмом. Решение данной проблемы требует объединение усилий государства и его граждан и огромных ресурсов. Однако следует помнить: такие проблемы невозможно решить в краткосрочном периоде времени, на это потребуются десятилетия. Но люди живут здесь и сейчас, они не хотят ждать. В этих условиях вполне популярными могут стать призывы к анархии, которая начинает восприниматься как радикальное и эффективное решение существующих проблем. Именно это и случилось в США. Люди, преимущественно с чёрным цветом 
кожи, начинают нарушать законы. Например, совершаются погромы магазинов. Владелец русского ресторана Pushkin в американском городе Сан-Диего Айк Газарян с помощью вооружённых друзей смог защитить своё заведение от погромщиков и мародеров. По словам Газаряна, к нему на помощь приехали 10-12 вооруженных людей, которые встали перед входом в заведение и начали ждать подхода толпы. «Всего на нас шла примерно тысяча человек. До того, как они дошли до нас, они сломали кучу магазинов», - рассказал Газарян. Протестующие ходили рядом с рестораном до двух часов ночи, но так и не решились на него напасть, утверждает предприниматель. Также, по его словам, они защитили от разгрома расположенный рядом ликёро-водочный магазин [21].

Интересная и чрезвычайно поучительная история произошла в Калифорнийском университете в Лос-Анджелесе (UCLA). Там отстранили от работы профессора Гордона Кляйна после того, как он отказался упрощать экзамены тёмнокожим студентам.

В течение 39 лет профессор преподавал бухгалтерское дело. После резонанса со смертью афроамериканца Джорджа Флойда некие «нечёрные союзники чёрных студентов» направили ему письмо, в котором попросили или сделать поблажки темнокожим при выставлении оценок во время онлайн-экзамена, или продлить дедлайны по квалификационным работам. В письме пояснялось, что студенты сейчас заняты протестами. Кляйн отказался идти на уступки. В защиту своей позиции он привёл слова лидера Движения за гражданские права темнокожих Мартина Лютера Кинга, который призывал отказаться от особого отношения к людям по цвету кожи. К тому же он отметил, что в онлайн-режиме ему вовсе непонятно, кто из его студентов темнокожий. Кляйн также задался вопросом: что делать, если студент смешанного происхождения?

После этого студенты выложили переписку в Сеть и создали петицию с требованием отстранить от работы Кляйна. В поддержку увольнения выступило около 20 тысяч человек. Профессору начали поступать угрозы. Университет на три недели отстранил преподавателя от работы за «насмешливое письмо» [22].

В марте руководство UCLA направило преподавателям сообщение с просьбой предоставить альтернативные формы проведения окончательных оценок в связи с пандемией COVID-19. При этом не требовалось, чтобы профессора отменяли выпускные экзамены или освобождали учащихся из числа меньшинств от выполнения всех необходимых курсовых работ. Так что Кляйн ничего не нарушил.

Но самые знаковые события произошли в г. Сиэтл, штат Вашингтон, где возникла Автономная зона Капитолийского холма (CHAZ). Данная зона по своей сути представляет самопровозглашённую автономию, которая располагается на территории центральной части города и не подконтрольная каким-либо органам государственной власти. Активисты заявляют, что на территории зоны не действуют никакие официальные органы власти. Административные и полицейские функции исполняются инициативными гражданами. Таким образом, события в Сиэтле развиваются по радикальному сценарию.

Сначала «Автономную зону Капитолийского холма» возглавила Кшама Савант, которая является одним из лидеров ультралевой партии «Социалистическая альтернатива» (региональная секция троцкистской Интернациональной социалистической альтернативы). Выступает со стандартными леворадикальными популистскими лозунгами, в том числе легализация наркотиков и предоставление гражданства всем нелегальным иммигрантам. С ней в паре в качестве идеолога выступала радикальная активистка Никкита Оливер: лидер движения за ликвидацию тюрем, патриархата и превосходства белых. Дальше события начинают развиваться по каноническому сценарию, который заканчивается победой анархии. Руководство анклава очень недолго пребывало у власти. В «свободную зону» были приглашены тысячи бездомных, которых накормили и оставили ночевать в «народном департаменте», в качестве которого выступало захваченное полицейское управление города. Бомжи повели себя в соответствии с принятий в их среде моделью поведения: украли все продукты и сбежали. Глава CHAZ Савант вместо того, чтобы заниматься управлением территорией, собрала массовый митинг, на котором выступила с предложением, которое было абсолютно не интересно для его участников: ввести налог для защиты лесов в Амазонии. В итоге её освистали и прогнали, в ответ Савант пригрозила покончить жизнь самоубийством.

Об уровне подготовки руководителей CHAZ можно судить по декрету, согласно которому вводился запрет на употребление любой невеганской пищи.

Вполне закономерно, что в этих условиях было не избежать жёсткой борьбы за передел власти. Итогом этой борьбы стал выход на первый план представителей чёрного криминала. Для этого была сформирована многочисленная группа боевиков, которая сразу же начинает заниматься поборами. За обеспечение безопасности магазина был установлен своего рода налог в 500 долл., что по своей сути 
есть обычный рэкет. В социальных сетях было размещено приглашение прибыть в Сиэтл всем сочувствующим, у которых есть оружие. Однако сразу было неясно, чем будут кормить этих добровольцев, так как продовольствие было разворовано бомжами [23].

Президент США Дональд Трамп раскритиковал действия местных властей города Сиэтл, заявив, что город захватили «внутренние террористы» и «мерзкие анархисты». Трамп отметил, что «левого радикала», губернатора штата Джея Инсли и мэра Сиэтла Дженни Даркан «разыграли и высмеяли» на «невиданном для страны уровне». Американский лидер потребовал «вернуть город» под власть законного руководства немедленно, иначе он сделает это сам. В ответ на это губернатор штата Джей Инсли заявил, что «человек, полностью неспособный управлять, должен держаться подальше от дел штата Вашингтон». Мэр Сиэтла Дженни Даркан, в свою очередь, посоветовала Трампу «вернуться в свой бункер», чтобы «все были в безопасности». Таким образом, все три официальных актора этих событий: государство, штат, власти города оказались бессильными перед волной анархичного протеста [24].

Финал этой истории вполне закономерен: первого июля полиция провела операцию по зачистке Автономной зоны Капитолийского холма. CHAZ была быстро и без особого сопротивления со стороны протестующих ликвидирована.

Таким образом, анархисты в который уже раз продемонстрировали свою неспособность к практическому решению существующих в обществе проблем. Можно констатировать, что достаточно красивые теоретические построения сторонников анархизма не выдерживают проверки практикой. Человек вынужден жить в обществе. Человек обязан выполнять правила, принятые в обществе, в котором он живёт и работает, общается с другими людьми. Эта суровая необходимость налагает на каждого человека необходимость смириться с теми жертвами и потерями, которые связаны с жизнью в обществе. Эти потери и жертвы компенсируются получаемыми выгодами от жизни в обществе. Жизнь в обществе совершенно невозможна без применения силы и принуждения против тех, кто не желает жить по правилам данного общества. Сразу делаем оговорку, что здесь речь не идёт об обществе, которое организовано по принципу диктатуры. Здесь восстание против государства может оказаться единственным вариантом решения проблемы обеспечения реальной свободы. Таким образом, общество предполагает наличие государства и правительства.

Л. фон Мизес отмечает: теория анархизма базируется на положении о том, что «можно достаточно спокойно избавиться от всякой формы принуждения и строить общество всецело на добровольном соблюдении морального кодекса. Анархисты считают государство, закон и правительство излишними институтами в социальной системе, которая бы действительно служила на благо всем людям, а не только особым интересам привилегированного меньшинства» [25. С. 39]. Люди никогда не будут добровольно выполнять правила, которые налагают на их действия какие-то ограничения. Невозможно и не нужно спорить с Мизесом в его утверждении: «Анархизм не понимает истинной природы человека. Он был реален только в мире ангелов и святых [25. С. 39].

Последние события в США являются ещё одним ярким и бесспорным подтверждением этого постулата. Без объективно обоснованного принуждения существование и нормальное развитие общества невозможно.

\section{СПИСОК ЛИТЕРАТУРЫ}

1. Ницше Ф. Так говорил Заратустра. СПб.: Азбука-классика, 2004. 336 с.

2. Гольдман Э. Анархизм / пер. с англ. М.: Голос труда, 1920. URL: https://ru.theanarchistlibrary.org/library/ emma-goldman-anarhizm.

3. Гоббс Т. Левиафан, или материя, форма и власть государства церковного и гражданского. URL: https://www.civisbook.ru/files/File/Gobbs Leviafan.pdf.

4. Кропоткин П.А. Анархия: сборник / сост. и предисл. Р.К. Баландина. М.: Айрис-пресс, 2002.576 с. URL: http://www.belousenko.com/books/kropotkin/kropotkin_anarkhija.htm.

5. Кропоткин П.А. Нравственные начала анархизма. URL: https://libcat.ru/knigi/nauka-i-obrazovanie/filosofiya/ 263534-petr-kropotkin-nravstvennye-nachala-anarhizma.html.

6. Кропоткин П.А. Хлеб и воля. URL:http://sbiblio.com/BIBLIO/archive/kropotkin_hleb/00.aspx.

7. Кропоткин П.А. Письмо Л.А. Шишко 6 декабря 1890 г. URL:https://biography.wikireading.ru/292506.

8. Ленин В.И. Задачи союзов молодёжи (Речь на III съезде Российского коммунистического союза молодёжи) 2 октября 1920 г. // Полн. собр. соч. М.: Политиздат, 1981. Т. 41. С. 298-318.

9. Вебер М. Политика как призвание и профессия. URL: https://www.bookol.ru/nauka_obrazovanie/filosofiya/ 136872/fulltext.htm.

10. Забастовка шахтеров Уэльса: 20 лет спустя. URL: http://news.bbc.co.uk/hi/russian/uk/newsid_4320000/ 4320529.stm. 
11. Хомский Н. Оптимизм вопреки отчаянию / пер. с англ. Д.С. Дамте. М.: РИПОЛ классик, 2018. 288 с

12. Хардт М., Негри А. Империя / пер. с англ., под ред. Г.В. Каменской, М.С. Фетисова. М.: Праксис, 2004.440 с.

13. Козлова Н.Н. Витальность как социально-философская проблема // Общественные науки и современность, 1998. № 2. C. 95-106.

14. Тоффлер Э. Будущее труда. Интервью. URL:https://gtmarket.ru/library/articles/2502.

15. Bakunin M. Marxism, Freedom and the State. Freedom Press, London; 1950. URL: https://www.marxists.org/reference/ archive/bakunin/works/mf-state/.

16. Malatesta E. The Anarchist Revolution. Polemical Articles 1924-1931. London: Freedom Press, 1974. URL: https://libcom.org/files/Malatesta\%20-\%20The\%20Anarchist\%20Revolution.pdf.

17. Кропоткин П.А. Государство, его роль в истории / [соч.] Петра Кропоткина; пер. под ред. авт. - Женева, 1904. 75 c. URL: http://elib.shpl.ru/ru/nodes/54130-kropotkin-p-a-gosudarstvo-ego-rol-v-istorii-zheneva-1904\#mode/inspect/ page/1/zoom/4.

18. Rocker R. Anarcho-syndicflism. Pluto Press. London. 1989. URL: https://ibcom.org/files/Rocker\%20-\%20 Anarcho-Syndicalism\%20Theory\%20and\%20Practice.pdf.

19. Разрыв в оплате труда белых и чёрных американцев больше, чем в 1979 году. URL: https://22century.ru/ society/33908.

20. Chasing the dream. URL:https://www.economist.com/leaders/2013/08/24/chasing-the-dream.

21. В США люди с оружием отстояли русский ресторан и ликёро-водочный магазин. URL: https://lenta.ru/news/ 2020/06/02/pushkin/.

22. UCLA college professor is suspended after refusing request for lenient marking of black students' final assessments due to the trauma they have suffered from George Floyd's death and civil unrest. URL: https://www.dailymail.co.uk/ news/article-8404307/Professor-suspended-refusing-request-lenient-marking-black-students-assessments.html.

23. URL: https://free-news.su/proisshestviya/46406-reper-soundcloud.

24. URL: https://lenta.ru/news/2020/06/12/ukhodi/.

25. Мизес Л. фон. Либерализм / пер. с англ. и комм. А.В. Куряева. Челябинск: Социум, 2014. 299 с.

Поступила в редакцию 10.06.2020

Матвеев Владимир Валентинович, доктор экономических наук, профессор

ФГБОУ ВО «Удмуртский государственный университет»

426034, Россия, г. Ижевск, ул. Университетская, 1 (корп. 4)

E-mail: mtv956@yandex.ru

\title{
V.V. Matveev
}

\section{ANARCHY AS AN INSTITUTIONAL DENIAL OF THE STATE}

\author{
DOI: $10.35634 / 2412-9593-2020-30-4-494-502$
}

The article is devoted to the study of anarchist interpretations of the economy. This study is relevant for the reason that the modern state has proved to be very ineffective in solving the problems associated with the emergence and spread of the COVID-19 epidemic. The contradiction between the state as a political institution and the population of many countries has reached a new, extremely high, level of confrontation. The methodological base of the study is basic economic theories, including public sector and institutional economics. As a result, the author substantiated the conclusion that in the conditions of a severe crisis, when the state is unable to quickly solve new problems, negative judgments about the role of the modern state as a political institution that should solve socio-economic problems are formed quite quickly. Under these conditions, anarchist interpretations of the development of society are beginning to gain popularity, which, in principle, deny the need for the state. Anarchists, as a basic postulate, promote the position that people themselves, without any involvement of the state, are able to solve both personal and collective, and social problems. However, the course of events in the United States refutes this statement. In a situation where there is no state as an actor in social processes, real power passes to criminal groups which easily go to the most severe violence against citizens. The results of the study can be used to formulate state and regional economic policies, as well as in the course of teaching the subject "Institutional Economics".

Keywords: anarchy, society, state, violence, crisis, globalism, communism, economic institutions.

Received 10.06.2020

Matveev V.V., Doctor of Economics, Professor

Udmurt State University

Universitetskaya st., 1/4, Izhevsk, Russia, 426034

E-mail: mtv956@yandex.ru 